\title{
Fatal Injuries in the Slums of Nairobi and their Risk Factors: Results from a Matched Case-Control Study
}

\author{
Abdhalah Kasiira Ziraba, Catherine Kyobutungi, and Eliya \\ Msiyaphazi Zulu
}

\begin{abstract}
Injuries contribute significantly to the rising morbidity and mortality attributable to non-communicable diseases in the developing world. Unfortunately, active injury surveillance is lacking in many developing countries, including Kenya. This study aims to describe and identify causes of and risk factors for fatal injuries in two slums in Nairobi city using a demographic surveillance system framework. The causes of death are determined using verbal autopsies. We used a nested case-control study design with all deaths from injuries between 2003 and 2005 as cases. Two controls were randomly selected from the non-injury deaths over the same period and individually matched to each case on age and sex. We used conditional logistic regression modeling to identity individual- and community-level factors associated with fatal injuries. Intentional injuries accounted for about $51 \%$ and unintentional injuries accounted for $49 \%$ of all injuries. Homicides accounted for $91 \%$ of intentional injuries and $47 \%$ of all injury-related deaths. Firearms $(23 \%)$ and road traffic crashes $(22 \%)$ were the leading single causes of deaths due to injuries. About $15 \%$ of injuries were due to substance intoxication, particularly alcohol, which in this community comes from illicit brews and is at times contaminated with methanol. Results suggest that in the pervasively unsafe and insecure environment that characterizes the urban slums, ethnicity, residence, and area level factors contribute significantly to the risk of injury-related mortality.
\end{abstract}

KEYWORDS Fatal injuries, Slums, Kenya, Verbal autopsy, Violence, Road traffic crashes, Firearms, Case control study, Conditional logistic regression, Demographic surveillance system

\section{BACKGROUND}

Injuries are a major cause of death and disability globally. The global burden of disease and risk factors study estimated that injuries accounted for $11 \%$ and $8 \%$ of the total burden of disease and injury in low- and middle-income countries, respectively. ${ }^{1}$ Although developed countries have experienced a decrease in injuryrelated deaths over the last several decades, fatal injuries are becoming a major cause of death in the developing world. ${ }^{2-4}$ In Kenya, it was estimated that fatalities as a result of road traffic crashes increased by $578 \%$ between 1962 and $1992 .{ }^{5}$ A study

\footnotetext{
Ziraba is with the Faculty of Epidemiology and Population Health, Department of Population Studies, London School of Hygiene and Tropical Medicine, London, UK; Kyobutungi is with the African Population and Health Research Center, Nairobi, Kenya; Zulu is with the African Institute for Development Policy, Nairobi, Kenya.

Correspondence: Abdhalah Kasiira Ziraba, Faculty of Epidemiology and Population Health, Department of Population Studies, London School of Hygiene and Tropical Medicine, Room LG21, Keppel Street, London, WC1E 7HT, UK. (E-mail: abdhalah.ziraba@1shtm.ac.uk; akziraba@yahoo.com)
} 
carried out in two slums of Nairobi revealed that injuries contributed about $18 \%$ of the burden of disease measured as life years lost due to premature death (YLL) and ranked second to HIV/AIDS as a cause of death among individuals aged 5 years and above. $^{6}$

Unintentional injuries are often considered "accidents"; therefore, there is limited interest and investment in prevention efforts. Research elsewhere has shown, however, that well-planned and implemented interventions such as improvements in home, road, and workplace safety, backed by effective law enforcement can reduce morbidity and mortality due to injuries. ${ }^{7-9}$ In spite of this evidence, little attention has been given to this growing epidemic in the developing world in terms of research, policy, or public health interventions. ${ }^{10-12}$ For instance, while the current minimum health care package for Kenya has a component on injury care, ${ }^{13}$ there are no concrete suggestions on which curative, preventive, and promotive interventions should be implemented at the different levels of health care delivery. ${ }^{13,14}$ Resource allocation for interventions geared towards mitigation of the burden of injuries remains low in most parts of Africa. In Uganda, for instance, Bishai and colleagues showed that even though injuries from road traffic crashes were a major public health concern, and in spite of the low cost of road safety enforcement per death averted, ${ }^{15}$ the budgetary expenditure on road safety was only US $\$ 0.09$ per capita in 1998. ${ }^{16}$

Risk factors for fatal injuries are varied and may be context specific. Studies have shown that gender, age, household, and community/neighborhood factors may influence risk of injury. They have shown that young males, low social economic status, alcohol use, and others are all associated with risk of injury. ${ }^{17,18}$ Sub-Saharan Africa (SSA) is the world's fastest urbanizing region. ${ }^{19}$ The high rate of urbanization in SSA presents new dynamics to the epidemiology of injuries in several ways. First, the combination of poorly planned cities, poor state of roads amidst rapidly increasing traffic volumes, and ineffective law enforcement contribute to the increasing burden of road traffic crashes in the region. ${ }^{20-22}$ Second, few and ill-equipped emergency services and poor accessibility mean that injury victims are rarely given appropriate and timely treatment. Third, the pace of urbanization in SSA has outstripped economic growth and urban planning efforts resulting in the uncontrolled growth of slums that house the majority of the urban population. ${ }^{23}$ The socioeconomic pressures brought about by lack of opportunities and high levels of unemployment in the slums may push many young people into risky or violent activities to generate income. Elicit potent brews and other drugs which are common in slums not only can cause acute poisoning but also predispose individuals to other forms of injury. ${ }^{23}$ Other potential risks of injury may arise from unsafe households and workplaces and low levels of law enforcement.

While a number of community and hospital-based studies have shed light on the situation of injuries in Kenya, a lot remains to be done. ${ }^{5,20-22,24-26}$ Very few studies have been carried out to understand the global spectrum of injuries including the less common ones which in the urban Kenya context are fast becoming an important cause of death. ${ }^{24-26}$ Given the peculiarities of slums, residents are potentially at a heightened risk of injury; yet, none of the past studies have focused on these areas. Furthermore, there is paucity of literature on risk factors for fatal injuries in Kenya; yet, this information is needed for public health interventions. This study aimed at describing causes of fatal injuries and identifying associated risk factors in order to contribute to prevention efforts. 


\section{MATERIALS AND METHODS}

We used data generated from the Nairobi Urban Health and Demographic Surveillance System (NUHDSS), which the African Population and Health Research Center has been running in Viwandani and Korogocho slums in Nairobi City since August 2002. The NUHDSS monitors a population of over 60,000 people annually living in the two slums. The surveillance system documents health and demographic events (including births, deaths, and migration histories) in all registered households every 4 months. When a household member dies, the probable cause of death is established using the verbal autopsy approach. For each deceased household member, a death form is completed to report the event. Subsequently, a detailed verbal autopsy interview is conducted by trained interviewers normally within 6 weeks after death. The interview is conducted with a close relative or other individual with knowledge of the circumstances leading up to the death, including symptoms experienced and treatment received by the deceased person prior to death. The deceased's medical records are reviewed if available. Three physicians review the completed verbal autopsy questionnaires and assign the probable cause of death based on the verbal autopsy analysis protocol. An abridged version of the 10th International Classification of Diseases is used to assign cause of death. Further details of the verbal autopsy approach have been described elsewhere. ${ }^{27,28}$

In this study, we used a nested case-control study design to identify factors associated with mortality from injuries. Deaths from injuries, also referred to as deaths from external causes, were identified as the cases while deaths from natural causes were considered controls. From the NUHDSS database, we identified all individuals who died from injuries between January 2003 and December 2005. The total number of deaths due to injuries was 134 . For each case, we randomly selected two controls from the longitudinal NUHDSS database of people that had died of other causes within the same period as the controls and individually matched them to cases on sex and age category. A total of 22 cases had only one control due to insufficient deaths from natural causes among males aged 5-19 years. We conducted descriptive analyses of all deaths that occurred as a result of injury. These analyses included distribution of cases and controls by demographic characteristics and distribution of intent and actual causes of injury. In addition, we ran two conditional logistic regression models. In the first (Model 1), we included area of residence variables to assess the effect of living in parts of the slum communities on risk of getting a fatal injury. The community levels factors were (1) slum of residence, (2) the proportion of residents in a village (in which the study participants resided at the time of death) in the lowest wealth index tercile, and (3) the proportion of singleperson households in the village. In the second (Model 2), we included individual level variables as well as community level factors. Individual level variables included ethnicity (Kikuyu, Kamba, Luhya, Luo, Others), wealth index (terciles), year of death (2003-2005), and mode of entry into the NUHDSS (birth, initial enumeration at the beginning of the NUHDSS, and in-migration after the start of the NUHDSS). These variables were extracted from the NUHDSS database.

\section{RESULTS}

\section{Descriptive Characteristics of Study Participants}

Two hundred and forty six controls were matched to the 134 cases. Details about the characteristics of the study participants are shown in Table 1 . Out of all the 
TABLE 1 Percentage distribution of cases and controls by socio-demographic characteristics, Nairobi DSS 2003-2005

\begin{tabular}{|c|c|c|c|}
\hline & Cases $(N=134)$ & Controls $(N=246)$ & Chi squared \\
\hline Variables & Percentage & Percentage & ( $P$ value) \\
\hline \multicolumn{4}{|l|}{ Age (years) } \\
\hline Less than 5 & 6.0 & 6.5 & \multirow[t]{5}{*}{$4.7(0.320)$} \\
\hline $5-9$ & 4.5 & 3.7 & \\
\hline 10-19 & 13.4 & 6.9 & \\
\hline 20-39 & 53.7 & 58.5 & \\
\hline $40+$ & 22.4 & 24.4 & \\
\hline \multicolumn{4}{|l|}{ Gender } \\
\hline Female & 11.9 & 13.0 & \multirow[t]{2}{*}{$0.1(0.765)$} \\
\hline Male & 88.1 & 87.0 & \\
\hline \multicolumn{4}{|l|}{ Slum } \\
\hline Korogocho & 47.8 & 66.3 & \multirow[t]{2}{*}{$12.3(<0.001)$} \\
\hline Viwandani & 52.2 & 33.7 & \\
\hline \multicolumn{4}{|l|}{ Ethnicity } \\
\hline Kikuyu & 48.5 & 27.2 & \multirow[t]{5}{*}{$29.0(<0.001)$} \\
\hline Kamba & 16.4 & 11.0 & \\
\hline Luhya & 10.5 & 13.4 & \\
\hline Luo & 16.4 & 39.8 & \\
\hline Others & 8.2 & 8.5 & \\
\hline \multicolumn{4}{|l|}{ Wealth index } \\
\hline Poorest & 32.8 & 33.7 & \multirow[t]{4}{*}{$1.6(0.440)$} \\
\hline Middle & 37.3 & 31.3 & \\
\hline Wealthiest & 29.9 & 35.0 & \\
\hline Total & $134(100.0)$ & $246(100.0)$ & \\
\hline
\end{tabular}

deaths by injury, only $12 \%$ were females, indicating that proportionately more males die of injuries than females. The distribution of cases and controls by area of residence was significantly different with $48 \%$ of cases being residents of Korogocho and $52 \%$ residents of Viwandani compared to $66 \%$ and $34 \%$ among controls for Korogocho and Viwandani, respectively $(p<0.001)$. There was no significant difference in the distribution of cases and controls by wealth status. Regarding ethnicity, there was a significantly higher proportion of individuals from the Kikuyu ethnic group among cases than in the controls, while the reverse was true for the Luo.

\section{Distribution of Causes of Injury}

Slightly more than half of the injury deaths were intentional and predominantly due to homicide (Table 2). Intentional injuries from firearms and blunt force trauma were the most common forms of homicide, accounting for about $40 \%$ of all injuries. Road traffic crashes accounted for $46 \%$ of unintentional injury deaths and for more than a fifth of all injury deaths. Unintentional alcohol and others forms of poisoning also contributed a sizeable proportion to the overall injury deaths $(12 \%)$. Overall, firearm injuries contributed the largest share of mortality due to injuries at $23 \%$, followed by road traffic crashes at $22 \%$. Of the 69 cases of intentional injuries, six were suicide cases, comprising $9 \%$ of intentional injuries (Figure 1). Overall homicides comprised $47 \%$ of all fatal injuries. 
TABLE 2 Distribution of causes of injury by intention among cases, Nairobi DSS 2003-2005

\begin{tabular}{|c|c|c|c|c|c|c|}
\hline \multirow[b]{2}{*}{ Mechanism of injury } & \multicolumn{2}{|c|}{$\begin{array}{l}\text { Intentional injuries } \\
(N=69)\end{array}$} & \multicolumn{2}{|c|}{$\begin{array}{l}\text { Unintentional injuries } \\
(N=65)\end{array}$} & \multicolumn{2}{|c|}{ Total $(N=134)$} \\
\hline & Number & Percentage & Number & Percentage & Number & Percentage \\
\hline Burns & 2 & 2.9 & 10 & 15.4 & 12 & 9.0 \\
\hline $\begin{array}{l}\text { Road Traffic } \\
\text { Crashes }\end{array}$ & 0 & 0.0 & 30 & 46.2 & 30 & 22.4 \\
\hline Firearm & 30 & 43.5 & 1 & 1.5 & 31 & 23.1 \\
\hline $\begin{array}{l}\text { Blunt force } \\
\text { trauma }\end{array}$ & 23 & 33.3 & 1 & 1.5 & 24 & 17.9 \\
\hline Cuts/stabs & 8 & 11.6 & 0 & 0.0 & 8 & 6.0 \\
\hline $\begin{array}{l}\text { Alcohol/other } \\
\text { poisoning }\end{array}$ & 4 & 5.8 & 16 & 24.6 & 20 & 14.9 \\
\hline $\begin{array}{l}\text { Other causes: } \\
\text { (includes falls, } \\
\text { drowning, and } \\
\text { strangulation) }\end{array}$ & 2 & 2.9 & 7 & 10.8 & 9 & 6.7 \\
\hline Total & 69 & 100.0 & 65 & 100.0 & 134 & 100.0 \\
\hline
\end{tabular}

\section{Intentional injuries: Korogocho and Viwandani,} Nairobi DSS 2003-2005

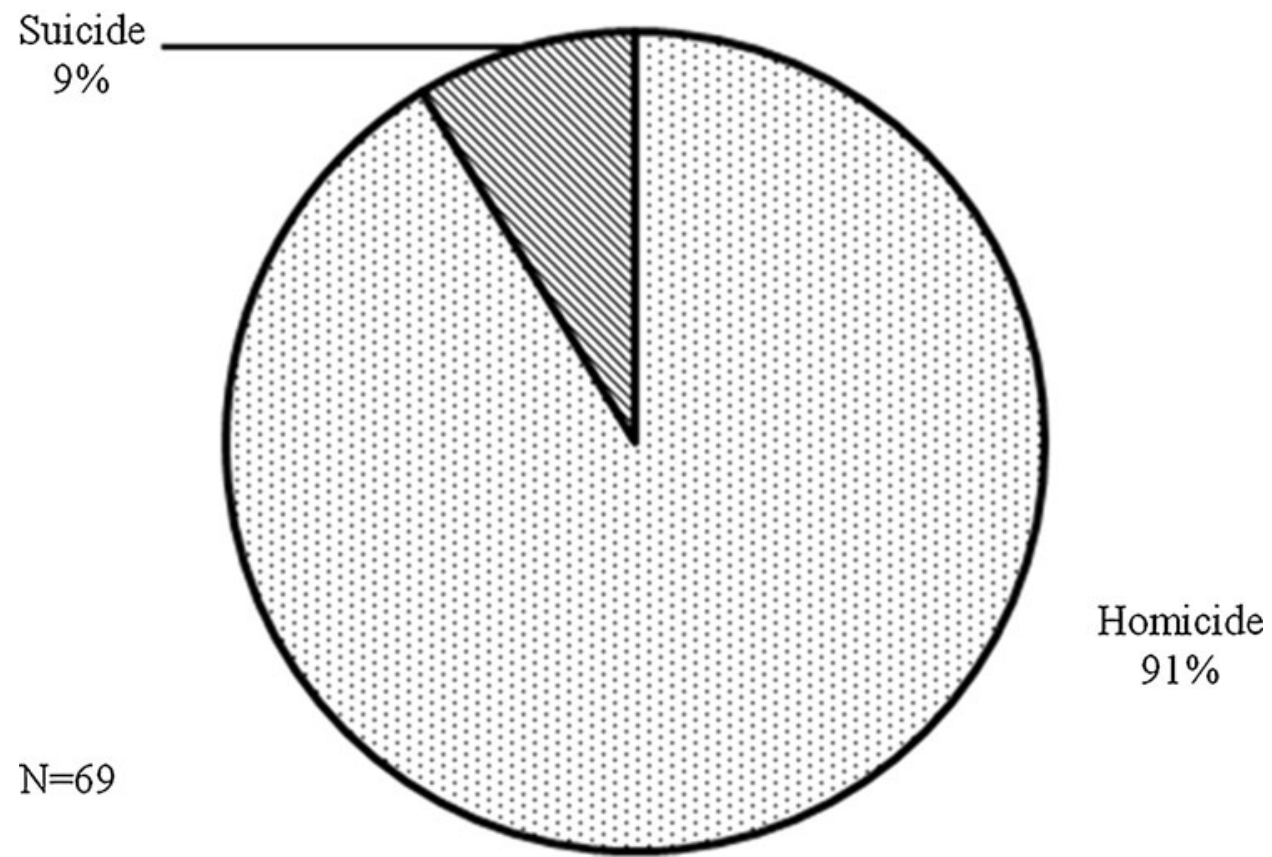

FIGURE 1. Distribution of fatal intentional injuries in Nairobi DSS 2003-2005. 


\section{Factors Associated with Death from Injuries}

Since age and sex were used for matching, these variables were not included in the multivariate analyses (results in Table 3). Slum of residence was significantly associated with risk of fatal injury $(\mathrm{OR}=5.23$, $p$ value $<0.001)$. However, the

TABLE 3 Unadjusted and adjusted (conditional logistic regression) odds ratios for risk factors for death from injury, Nairobi DSS 2003-2005

\begin{tabular}{|c|c|c|c|}
\hline Variables & $\begin{array}{l}\text { Unadjusted } O R \\
\text { for all variables } \\
{[95 \% \mathrm{Cl}]}\end{array}$ & $\begin{array}{l}\text { Adjusted OR for area } \\
\text { of residence variables } \\
{[95 \% \mathrm{Cl}] \text { —Model } 1}\end{array}$ & $\begin{array}{l}\text { Adjusted OR } \\
\text { for area of residence } \\
\text { and other variables } \\
{[95 \% \mathrm{Cl}] \text {-Model } 2}\end{array}$ \\
\hline \multicolumn{4}{|c|}{ Area of residence variables } \\
\hline \multicolumn{4}{|c|}{ Slum of residence } \\
\hline Korogocho & 1.00 & 1.00 & 1.00 \\
\hline Viwandani & $\begin{array}{l}5.23^{* * *} \\
{[2.64,10.34]}\end{array}$ & $\begin{array}{l}3.96^{* *} \\
{[1.53,10.25]}\end{array}$ & $3.21 *[1.18,8.71]$ \\
\hline \multicolumn{4}{|c|}{$\%$ in lowest SES in village } \\
\hline$\leq 15 \%$ & 1.00 & 1.00 & 1.00 \\
\hline $16-20 \%$ & $2.32[0.97,5.52]$ & $0.32[0.08,1.33]$ & $0.24[0.05,1.18]$ \\
\hline$>20 \%$ & $\begin{array}{l}5.59 * * * \\
{[2.46,12.67]}\end{array}$ & $0.23[0.04,1.18]$ & $0.25[0.04,1.46]$ \\
\hline \multicolumn{4}{|c|}{$\%$ single-person $\mathrm{HH}$ in village } \\
\hline$\leq 70 \%$ & 1.00 & 1.00 & 1.00 \\
\hline $71-75 \%$ & $\begin{array}{l}4.63^{* * *} \\
{[2.15,10.01]}\end{array}$ & $\begin{array}{l}5.41^{*} \\
{[1.43,20.47]}\end{array}$ & $4.02[1.00,16.17]$ \\
\hline$\geq 76 \%$ & $\begin{array}{l}13.71^{* * *} \\
{[5.17,36.34]}\end{array}$ & $\begin{array}{l}20.02^{* * *} \\
{[4.37,91.63]}\end{array}$ & $\begin{array}{l}13.52^{* *} \\
{[2.76,66.20]}\end{array}$ \\
\hline \multicolumn{4}{|c|}{ Socio-demographic variables } \\
\hline Kikuyu & 1.00 & & 1.00 \\
\hline Kamba & $0.82[0.38,1.76]$ & & $0.73[0.30,1.73]$ \\
\hline Luhya & $\begin{array}{l}0.35^{*} \\
{[0.16,0.78]}\end{array}$ & & $0.38^{*}[0.15,0.96]$ \\
\hline Luo & $\begin{array}{l}0.18^{* * *} \\
{[0.10,0.36]}\end{array}$ & & $\begin{array}{l}0.25^{* * *} \\
{[0.11,0.55]}\end{array}$ \\
\hline Others & $\begin{array}{l}0.37^{*} \\
{[0.15,0.93]}\end{array}$ & & $0.43[0.15,1.25]$ \\
\hline \multicolumn{4}{|l|}{ Wealth index } \\
\hline Poorest & 1.00 & & 1.00 \\
\hline Middle & $1.35[0.79,2.31]$ & & $1.85[0.95,3.61]$ \\
\hline Wealthiest & $0.87[0.51,1.50]$ & & $0.97[0.50,1.87]$ \\
\hline \multicolumn{4}{|c|}{ Year death occurred } \\
\hline 2003 & 1.00 & & 1.00 \\
\hline 2004 & $1.21[0.75,1.94]$ & & $1.15[0.64,2.06]$ \\
\hline 2005 & $1.05[0.58,1.91]$ & & $0.83[0.40,1.74]$ \\
\hline \multicolumn{4}{|c|}{ Mode of entry in surveillance } \\
\hline Enumeration & 1.00 & & 1.00 \\
\hline Birth & $0.84[0.15,4.68]$ & & $0.59[0.08,4.23]$ \\
\hline In-migration & $1.12[0.69,1.82]$ & & $1.14[0.63,2.06]$ \\
\hline
\end{tabular}

$O R$ odds ratio, $\mathrm{Cl}$ confidence interval, SES socio-economic status, $\mathrm{HH}$ household ${ }^{*} p<0.05,{ }^{* *} p<0.01,{ }^{* * *} p<0.001$ 
strength of the association was attenuated upon controlling for other variables $(\mathrm{OR}=3.21 ; P$ value $=0.022)$. Viwandani residents were about 3.2 times more likely to die from injuries than Korogocho residents (Model 2). Living in a village with over $20 \%$ of residents in the lowest socioeconomic status was significantly associated with 5.6 times higher risk of death from injury, but this became insignificant after controlling for covariates. Residing in a village with a high proportion of single-person households $(>70 \%)$ conferred a significantly higher risk of death from injury. Upon controlling for covariates, only individuals living in villages with greater than $75 \%$ of households being single-member had a significantly higher risk of death from injuries $(\mathrm{OR}=13.52, P$ value $=0.001)$. All ethnic groups had lower odds of dying from injuries than the Kikuyu. The largest significant difference was observed between the Kikuyu and Luo, whereby the latter had about $75 \%$ lower odds of death from injury as was the former $(\mathrm{OR}=0.25, P$ value $<0.001)$. Differences between the Kikuyu and Kamba were not significant. There were no significant associations for the other variables such as mode of entry in surveillance, wealth index, and year of death.

\section{DISCUSSION}

This study describes the distribution of injury deaths among a population of residents in two urban slums in Nairobi city, which typifies the health challenges associated with increasing urbanization and urban poverty in Africa. We explored differences in the distribution of deaths through injury by individual characteristics and by whether the injury was intentional or unintentional. We also examined factors associated with injury-related deaths, relative to other deaths in the study population. We found that intentional injuries $(51 \%)$ were as common as unintentional ones $(49 \%)$. The proportion of injuries $(51 \%)$ due to violence (suicide and homicide) was higher than most reported in the region. A hospital-based study in Democratic Republic of the Congo, Kenya, Nigeria, Uganda, and Zambia revealed that $40 \%$ of injury deaths were due to violence, ${ }^{29}$ while another study in five Kampala Hospitals Uganda showed that deaths due to violence related injuries accounted for only $14 \% .{ }^{30}$ While these differences might reflect the reality in terms of occurrence of deaths due to violence, it might also be a measurement issue. Many deaths due to violence may not make it to the hospital; therefore, using hospital records alone may underestimate the extent of the problem.

Injuries due to violence are on the increase in many parts of the world, including Africa. Causes range from domestic violence, sexual assault, suicide, and effects of war. Global burden of disease estimates indicate that, in 2001, approximately 1.6 million people died as a result of violence, with $34 \%$ of these being homicides. ${ }^{1}$ The World Health Organization estimates that more than $90 \%$ of all violence-related deaths occur in the developing world. ${ }^{1}$ A previous study conducted in the same two slums found a high-mortality burden due to injuries accounting for about $18 \%$ of the share of YLL due to premature death among individuals 5 years and older. ${ }^{6}$

The most striking finding is that violence-related deaths are more common than road traffic crashes. This is in contrast with what has been reported in most of the literature from SSA where, with the exception of South Africa, road traffic accidents account for $40-50 \%$ of all injury-related deaths. ${ }^{30,31}$ The proportion of homiciderelated injuries estimated in this study population $(47 \%)$ is much higher than the $34 \%$ observed globally. ${ }^{1}$ The high rate of intentional, violence-related injuries and the fact that firearms are the single most common cause of injury accounting for 
close to a quarter of all injury deaths, reflect the high levels of insecurity experienced by residents in urban slums. It is worth noting here that many of firearm deaths occur during fire exchanges between armed criminals and the police. Most of the blunt object injuries (accounting for $18 \%$ of all injury deathsresults not shown) were sustained in the course of "mob justice" which is a reflection of the perceived failure by the system to offer justice. Community policing initiatives to counter the poor presence of formal law enforcement mechanisms may reduce this practice.

Understanding the factors associated with mortality from injuries is an important step in the quest for solutions to improve the overall health and wellbeing of residents in the rapidly growing slums. Our results showed that residents of Viwandani slum were at a higher risk of an injury death than those from Korogocho. Various studies in the two slums have shown a mortality disadvantage for Korogocho residents, ${ }^{6,32}$ and so our findings are a departure from the expectation. Viwandani is predominantly occupied by young, highly mobile labor migrants. High mobility, higher proportion of single adults, split households, and a fast-paced cash economy where people spend long hours at work (or looking for work) mean that Viwandani residents are more likely to have loose social ties and weak social support structures resulting in reduced social cohesion. Korogocho is a more established settlement with the majority of the population staying for long periods with their families, and hence having stronger social ties that are known to be protective against violence-related injury and death. ${ }^{33-35}$ The finding that individuals living in areas with a higher concentration of one-person households have a higher risk of death from injuries highlights the absence of "communal security" conferred by neighborhoods. This finding should, however, be interpreted with caution given the wide confidence intervals around the estimate.

The finding of a higher risk of injury deaths among the Kikuyu ethnic group was rather surprising. In previous studies in the same two slums, the Luo have been shown to have a mortality disadvantage and the Kikuyu a mortality advantage, ${ }^{6}$ but in this study, the reverse is true. It is not clear why this is the case. Speculatively, this might be related to the crackdown by the police force and community vigilantes on the membership of an outlawed sect (Mungiki) whose members come from the Kikuyu tribe. Further studies are recommended to elucidate the reasons why the Kikuyu seem to be more likely to die from injuries.

There is a surprising absence of association between the risk of dying from injury and other established individual level risk factors like socioeconomic and migration status. It is possible that area level factors play a bigger role than individual level factors in such an environment to the extent that factors that would confer individual level protection are rendered irrelevant in the insecure, socially fragmented environment that prevails in slums.

\section{Limitations}

Although the intention was to have two controls for each case, this was not possible due to inadequate numbers of deaths due to natural causes, and this could have reduced the power of the study as evidenced by some of the estimates having wide $95 \%$ confidence intervals. Misclassification of cause of death cannot be ruled out in cases where injury did not result in immediate death. Available data do not also include measures of substance use and other risk factors that may provide a more nuanced understanding of the drivers of injury-related morbidity and mortality. 


\section{CONCLUSION}

Homicides account for nearly half of injury-related deaths in the two slums studied. Area of residence and ethnicity emerge as significant predictors of injury-related mortality. Understanding individual- and community-level drivers of variations in injury-related morbidity and mortality is important for the design of preventive interventions. For these communities, it is important to explore further why specific ethnic groups (e.g., Kikuyu) and residential areas are adversely affected and consequently target interventions through creation of awareness, community mobilization, increased policing and ensuring that emergency services are accessible in a timely manner.

\section{ACKNOWLEDGEMENTS}

We wish to extend our thanks to the Korogocho and Viwandani communities for their participation in the NUHDSS. We would also like to appreciate the generous financial support from The Wellcome Trust (grant-GR078530MA) for the Urbanization, Poverty and Health Dynamics in sub-Saharan Africa research program and core support from the Hewlett Foundation (grant-2006-8376) and the Rockefeller Foundation (grant number 2007-HE 008) that partly support the NUHDSS.

\section{REFERENCES}

1. Mathers CD, Lopez AD, Murray CJL. The burden of disease and risk factors. In: Lopez $\mathrm{AD}$, Mathers CD, Ezzati M, Jamison DT, Murray CJL, eds. Global Burden of Disease and Risk Factors. New York, NY: Oxford University Press; 2006.

2. Murray CJ, Lopez AD. Evidence-based health policy-lessons from the Global Burden of Disease Study. Science. 1996; 274(5288): 740-743.

3. Murray CJ, Lopez AD. Mortality by cause for eight regions of the world: Global Burden of Disease Study. Lancet. 1997; 349(9061): 1269-1276.

4. Mathers CD, Boerma T, Ma Fat D. Global and regional causes of death. Br Med Bull. 2009; 92(1): 7-32.

5. Odero W, Garner P, Zwi A. Road traffic injuries in developing countries: a comprehensive review of epidemiological studies. Trop Med Int Health. 1997; 2(5): 445-460.

6. Kyobutungi C, Ziraba AK, Ezeh A, Ye Y. The burden of disease profile of residents of Nairobi's slums: results from a Demographic Surveillance System. Popul Health Metr. 2008; 6: 1.

7. Kendrick D, Coupland C, Mulvaney C, et al. Home safety education and provision of safety equipment for injury prevention. Cochrane Database Syst Rev. 2007; 1: CD005014.

8. Peacock C. International policies on alcohol-impaired driving: a review. Int J Addict. 1992; 27(2): 187-208.

9. Ruta D, Beattie T, Narayan V. A prospective study of non-fatal childhood road traffic accidents: what can seat restraint achieve? J Public Health Med. 1993; 15(1): 88-92.

10. Nordberg E. Injuries as a public health problem in sub-Saharan Africa: epidemiology and prospects for control. East Afr Med J. 2000; 77(12 Suppl): S1-S43.

11. Forjuoh SN, Zwi AB, Mock CN. Injury control in Africa: getting governments to do more. Trop Med Int Health. 1998; 3(5): 349-356.

12. Smith GS, Barss P. Unintentional injuries in developing countries: the epidemiology of a neglected problem. Epidemiol Rev. 1991; 13: 228-266.

13. MoH-Kenya. Reversing the Trends: The Second National Health Sector Strategic PlanNHSSP-II, 2005-2010. Nairobi, Kenya: Ministry of Health; 2005. 
14. MoH. Taking the Kenya Essential Package for Health to the Community. Nairobi: Ministry of Health, Kenya; 2006.

15. Bishai D, Asiimwe B, Abbas S, Hyder AA, Bazeyo W. Cost-effectiveness of traffic enforcement: case study from Uganda. Inj Prev. 2008; 14(4): 223-227.

16. Bishai D, Hyder AA, Ghaffar A, Morrow RH, Kobusingye O. Rates of public investment for road safety in developing countries: case studies of Uganda and Pakistan. Health Policy Plan. 2003; 18(2): 232-235.

17. WHO. World Report on Violence and Health. Geneva, Switzerland: World Health Organization; 2002.

18. Cherpitel CJ. Epidemiology of alcohol-related trauma. Alcohol Health Res World. 1992; 16: 191-196.

19. UN-HABITAT. The Challenge of Slums: Global Report on Human Settlements. Nairobi, Kenya: UN-HABITAT; 2003.

20. Odero W, Khayesi M, Heda PM. Road traffic injuries in Kenya: magnitude, causes and status of intervention. Inj Control Saf Promot. 2003; 10(1-2): 53-61.

21. Odero W. Alcohol-related road traffic injuries in Eldoret, Kenya. East Afr Med J. 1998; 75(12): 708-711.

22. Odero W. Road traffic accidents in Kenya: an epidemiological appraisal. East Afr Med J. 1995; 72(5): 299-305.

23. United Nations Human Settlements Programme (UN-Habitat). The Challenge of SlumsGlobal Report on Human Settlements 2003. Nairobi, Kenya: Earthscan; 2003.

24. Arap Mengech HN. Alcohol-related road traffic accidents. East Afr Med J. 1997; 74(11): 673-674.

25. Muniu E, Katsivo MN, Mwaura LW, Amuyunzu M. Fatal non-transport injuries in Nairobi, Kenya. East Afr Med J. 1994; 71(6): 346-349.

26. Oburra HO. Causes of ear trauma in Kenyan patients. East Afr Med J. 1998; 75(6): 319_ 321.

27. Setel PW, Rao C, Hemed Y, et al. Core verbal autopsy procedures with comparative validation results from two countries. PLoS Med. 2006; 3(8): e268.

28. Setel PW, Whiting DR, Hemed Y, et al. Validity of verbal autopsy procedures for determining cause of death in Tanzania. Trop Med Int Health. 2006; 11(5): 681-696.

29. Zavalaa DE, Bokongo S, John IA, et al. Implementing a hospital based injury surveillance system in Africa: lessons learned. Med Confl Surviv. 2008; 24(4): 260-272.

30. Kobusingye OC, Guwatudde D, Owor G, Lett RR. Citywide trauma experience in Kampala, Uganda: a call for intervention. Inj Prev. 2002; 8(2): 133-136.

31. Otieno T, Woodfield JC, Bird P, Hill AG. Trauma in rural Kenya. Injury. 2004; 35(12): 1228-1233.

32. Ziraba AK, Madise N, Mills S, Kyobutungi C, Ezeh A. Maternal mortality in the slums of Nairobi city: what do we know? Reprod Health. 2009; 6: 6.

33. Kennedy BP, Kawachi I, Prothrow-Stith D, Lochner K, Gupta V. Social capital, income inequality, and firearm violent crime. Soc Sci Med. 1998; 47(1): 7-17.

34. Sampson RJ, Raudenbush SW, Earls F. Neighborhoods and violent crime: a multilevel study of collective efficacy. Science. 1997; 277(5328): 918-924.

35. Zolotor AJ, Runyan DK. Social capital, family violence, and neglect. Pediatrics. 2006; 117(6): e1124-e1131. 